\title{
Water and Pathogenic Viruses Inactivation-Food Engineering Perspectives
}

\author{
Yrjö H. Roos ${ }^{1}$ \\ Received: 3 June 2020 / Accepted: 5 June 2020 / Published online: 20 June 2020 \\ (C) Springer Science+Business Media, LLC, part of Springer Nature 2020
}

\begin{abstract}
Water is an essential component of food structures and biological materials. The importance of water as a parameter affecting virion stability and inactivation has been recognized across disciplinary areas. The large number of virus species, differences in spreading, likelihood of foodborne infections, unknown infective doses, and difficulties of infective virus quantification are often limiting experimental approaches to establish accurate data required for detailed understanding of virions' stability and inactivation kinetics in various foods. Furthermore, non-foodborne viruses, as shown by the SARS-CoV-2 (Covid-19) pandemic, may spread within the food chain. Traditional food engineering benefits from kinetic data on effects of relative humidity (RH) and temperature on virion inactivation. The stability of enteric viruses, human norovirus ( $\mathrm{HuNoV})$, and hepatitis A (HAV) virions in food materials and their resistance against inactivation in traditional food processing and preservation is well recognized. It appears that temperature-dependence of virus inactivation is less affected by virus strains than differences in temperature and $\mathrm{RH}$ sensitivity of individual virus species. Pathogenic viruses are stable at low temperatures typical of food storage conditions. A significant change in activation energy above typical protein denaturation temperatures suggests a rapid inactivation of virions. Furthermore, virus inactivation mechanisms seem to vary according to temperature. Although little is known on the effects of water on virions' resistance during food processing and storage, dehydration, low RH conditions, and freezing stabilize virions. Enveloped virions tend to have a high stability at low RH, but low temperature and high RH may also stabilize such virions on metal and other surfaces for several days. Food engineering has contributed to significant developments in stabilization of nutrients, flavors, and sensitive components in food materials which provides a knowledge base for development of technologies to inactivate virions in foods and environment. Novel food processing, particularly high pressure processing (HPP) and cold plasma technologies, seem to provide efficient means for virion inactivation and food quality retention prior to packaging or food preservation by traditional technologies.
\end{abstract}

Keywords Foodborne viruses $\cdot$ Virus inactivation $\cdot$ Food processing $\cdot$ Food preservation $\cdot$ Water

\section{Introduction}

Viruses are intracellular, foreign, genetically structured particles of biological macromolecules which use biological functions of host cells to replicate, i.e., no replication occurs outside host cells. In other words, viruses are not organisms or living cells, although they contain genetic material providing viruses with an ability to replicate using their specific host cells. Properties of viruses, replication, and inactivation are significantly different from those of pathogenic

Yrjö H. Roos

yrjo.roos@ucc.ie

1 School of Food and Nutritional Sciences, University College Cork, Cork, Ireland microorganisms in foods. Microorganisms are individual living cells which use food materials as their growth medium. Viruses outside their host cells, however, exist as inactive virions, i.e., as particles with complete infective functions. Virions present biological mechanisms for entering their specific hosts' cells, where an infection causes the host cells to reproduce viral DNA or RNA and then release a large number of virus copies for spreading as new virions. Moreover, viruses do not change organoleptic properties of contaminated foods [25, 60], and quite often, the source of virus contamination and spread is unidentified [51]. A food engineering and safety concern is the retention of virus infectivity and infection risks within the food chain.

Viruses vary in size which is typically around $100 \mathrm{~nm}$ but the sizes among approximately 6600 classified virus species [18] may vary significantly from 20 to above $1000 \mathrm{~nm}$. 
Obviously, optical microscopes may not detect individual virions and images are typically obtained by electron microscopy. The genome of a virus is structured either in DNA or RNA sequences which with nucleoprotein are surrounded by a protein capsid. A number of viruses produce a lipid bilayer as an envelope around the capsid. Such envelope consists of phospholipids and proteins from cell membranes of their host cells. The small size, concentration, and a tiny infective dose of virions besides the need of host cells for reproduction of viral material result in challenges in studies analyzing virus survival and infectiousness in food, water, and the environment [60]. Viral inactivation studies often employ surrogate viruses to follow virus stability and inactivation. On the other hand, virus infections often result in serious illnesses which may be transmitted via the food chain, including food handling, premises and packaging, or even the food itself. Bivalve mollusks (shellfish) and fresh produce (hand-picked berries, fruits, vegetables), for example, are minimally processed foods which are often contaminated by viruses and, therefore, important sources of foodborne infections [15].

Multiplication of viruses occurs by production of viral genomes by virus-specific host cells. That is a viral DNA or RNA, or a number of genomes may be detected outside host cells after a particular treatment, but virus extraction and analytical methods to find whether the virion has remained active and infectious are limited [47, 52]. Such lack of methodology and unique multiplication route results in a significant difference between studies of viral and microbial stability, loss kinetics, or retention of nutrients and biologically active substances in food. Furthermore, bacteria growth or loss kinetics may be derived from numbers of growing cells following a treatment or sampling from surfaces while chemical analytical methods allow detection and studies of degradation kinetics of nutrients or other molecules in food. Likewise, one may find viral DNA or RNA in food or water, contact surfaces, food handling areas, and employees. The existence of viral genomes outside cells, however, does not confirm viability of virions when host cells become available. For such reasons, studies of infective virus concentrations must use plaque assays (e.g., $[24,57])$ or require cell cultures (e.g., [11]) to reproduce viral genomes besides extraction of a sufficient number or concentration of virions from a contaminated source [47]. Because of such challenges and large variation in experimental data, transmission routes of viruses as well as factors affecting viability of virions are poorly understood.

Transmission pathways of viral infections and data of their importance to food safety are of high value in food engineering. Foodborne transmissions of many nonenveloped virions causing gastroenteric viral illnesses have well-established links to contamination of ready-to-eat food by an infected food handler [15, 60]. Foodborne transmission of enveloped influenza viruses is also a possibility, although airborne spreading from infected carriers via surfaces, including foods and packaging, is a recognized risk, particularly at food handling and processing facilities $[15,47]$. According to FAO and WHO [15], major foodborne viruses cause infections in the gastrointestinal tract. Such viruses are typically transmitted in feces or vomitus. Noroviruses (NoV) and hepatitis A virus (HAV) are known as the most common foodborne causes of viral gastroenteritis along with Rotaviruses, Enteroviruses, and Astroviruses [5, 15, 25, 47]. Determination of an infective dose may present difficulties. The highly infective Human Norovirus (HuNoV) has an infective dose of 15 to 1300 genome copies or 1 to 10 virions [5]. One may note that $1 \mathrm{~g}$ of infected stool may contain $>10^{13} \mathrm{HuNoV}$ virions [5]. A large number of other viruses may show transmissions via food or water allowing them to replicate in the human intestine. Illness, however, may occur only after virions migrate to other organs, such as the liver or even the central nervous system (Enterovirus). Many virions survive food processing and even SARS-CoV and highly pathogenic avian influenza (HPAI) virus have been documented to show foodborne transmission $[15,25,47]$. Jalava [22] concluded in her analysis of initial transmissions of SARS-CoV-2 (Covid-19) that respiratory transmission was likely. She found food as an unlikely route. Poor ventilation was taken into account, but working practices, the cold chain, and possible condensation of aerosol particles or droplet settling on surfaces thereby leading to direct contamination and transmission via food or packaging contamination was not considered.

An infective viral contamination of a food is always a risk of a likely cause of an infection. In food engineering, there is a need to understand effects of treatments on virions as well as effects of food properties and storage conditions, including water activity, $\mathrm{a}_{\mathrm{w}}$, on virions. That is not the presence of viral genomes in foods as such, but the infective load of viruses, i.e., number of virions, is essential in understanding processing needs and food safety. Unfortunately, no rapid methodology for the detection of foodborne transmissions or virions in foods or food package headspace has been developed. Stability of viruses seems to depend strongly on whether they have a non-enveloped (naked) capsid (e.g., enteroviruses) or enveloped capsid (e.g., influenza and coronaviruses) [28]. Most viruses causing gastroenteritis show excellent stability in fresh products and may remain active throughout product shelf life and even several months in shellfish (Bosh et al., 2018). Moreover, chilled and frozen storage of foods can preserve viruses for months or years. On the other hand, numerous antiviral compounds are naturally present in various foods, as was reviewed by Bosch et al. [5] and Galanakis [16]. Such compounds may inactivate the spike proteins of viruses and disable their entry into host cells. In food processing, viruses are effectively destroyed by temperatures $>80^{\circ} \mathrm{C}$ which rapidly damage virus capsids. Free chloride and ozone cause strong damage to nuclei acids of viruses besides harmful effects on the capsid [59]. 
Virus stability and transmission routes are universal environmental issues which have a direct implication on food safety. Food industry has a need for information on viral stability throughout the food chain as well as understanding of viral degradation kinetics in various surroundings, including foods. Conversely, food engineers have developed technologies for food processing and preservation which require understanding of effects of electric fields, light and radiation, pressure, $\mathrm{pH}$, phase and state transitions, temperature, and other physicochemical parameters on bioactive substances, nutrients, and microorganisms. One example of high relevance of such technologies to virions' stability is dehydration by spray drying which uses aerosols and droplets of food liquids to produce stable particles. Besides physicochemical surroundings of virions in such food processing, water may significantly affect stability and degradation kinetics of virions [13]. Here, we summarize studies reporting on virus survival and degradation kinetics with critical evaluation of the importance of known data to understanding losses of virus infectivity in normal circumstances, and particularly as affected by water from a food engineering and safety perspective. Furthermore, we emphasize virion stability and kinetics of loss of virion infectivity, including data for influenza A and SARS (Severe Acute Respiratory Syndrome) virions, and discussion of the new SARS-CoV-2 (Covid-19) virion stability. The overall benefits of general food engineering to studies of virions survival and stability are due to similarities in requirements with existing food processing treatments and preservation technologies which often aim at reducing microbial survival and growth without compromising food safety, nutritional value, and sensory pleasure.

\section{Foodborne Viruses}

\section{Classification of Viruses}

Taxonomy of viruses is the responsibility of the International Committee on Taxonomy of Viruses (ICTV) [18]. The ICTV Master Species list 2019 lists 4 realms, 9 kingdoms, 16 phyla, 2 subphyla, 36 classes, 55 orders, 8 suborders, 168 families, 103 subfamilies, 1421 genera, 68 subgenera, and 6590 species. Sometimes viruses may also be referred to as DNA and RNA viruses according to their genome composition.

Classification and general properties of most common food-related pathogenic viruses are given in Table 1 . Pathogenic viruses of significant concern to food safety are listed by FAO and WHO [15] as those that:

- Cause a high incidence of foodborne viral disease, based on currently available data (enteric viruses)

- Cause severe disease including significant mortality worldwide (pandemic)
- Have the potential for foodborne transmission and to pose a significant threat to public health (pandemic)

\section{Transmission of Viral Infections}

Viral transmissions are strongly related to the presence of water either as a transmission medium or with a structural and stabilizing function [28]. According to FAO and WHO [15], food hygiene guidelines, which have been optimized for prevention of bacterial infections, may not be effective for viruses. Foods may become contaminated by infective viral material through (i) human sewage and feces; (ii) infected food handlers; and (iii) animals for zoonotic viruses [15]. On the other hand, these transmission routes seem to primarily apply to direct contamination of food and inclusion of virions as part of the food. Several other routes of viral transmissions in modern food supply chain need to be considered. Such routes include food surfaces and packages, food manufacturing and distribution, food service establishments, and supermarkets [16].

Viral infections can be transmitted directly from contaminated foods, from the environment, and directly in aerosols and droplets emitted by infected hosts (Table 1). Food contamination often occurs via soil, water, and other direct routes as well as from infected persons or animals. Some enteric viruses, such as Human Norovirus (HuNoV) and enteroviruses may also transmit via aerosols and feces. The working environment is another important source for infections among employees, particularly at healthcare facilities [47] and also at refrigerated food premises, particularly at meat processing plants. Food engineers have skills and potential to respond and model aerosol composition and dehydration effects on virions' survival in emission and environment as well as during food processing and in manufacturing facilities. Pathogenic viruses may also be assumed to adhere strongly and subsequently survive on personal protective equipment (PPE) and protective clothing of employees depending on hydrophilic-hydrophobic as well as electrostatic properties of materials [27]. According to van Doremalen et al. [54], SARS-CoV-2 virions were more stable on plastic (half-life $>$ $6 \mathrm{~h}$, virus viability $>72 \mathrm{~h}$ ) and stainless steel than on aerosols and copper (half-life $\approx 1 \mathrm{~h}$ ) or cardboard (half-life $>3 \mathrm{~h}$ ). Such survival times are sufficient for virions stabilization by dehydration and effective release of concentrated, infective virions to result in secondary transmissions by dusting or direct contact from plastic (including polyester, PET, clothing) and other surfaces, including clothing.

Traditional food preservation using acidification, dehydration, or temperature control may not be sufficient to control foodborne viral infections, mainly because of highly resistant enteric viruses $[28,51]$. On the other hand, spreading of 


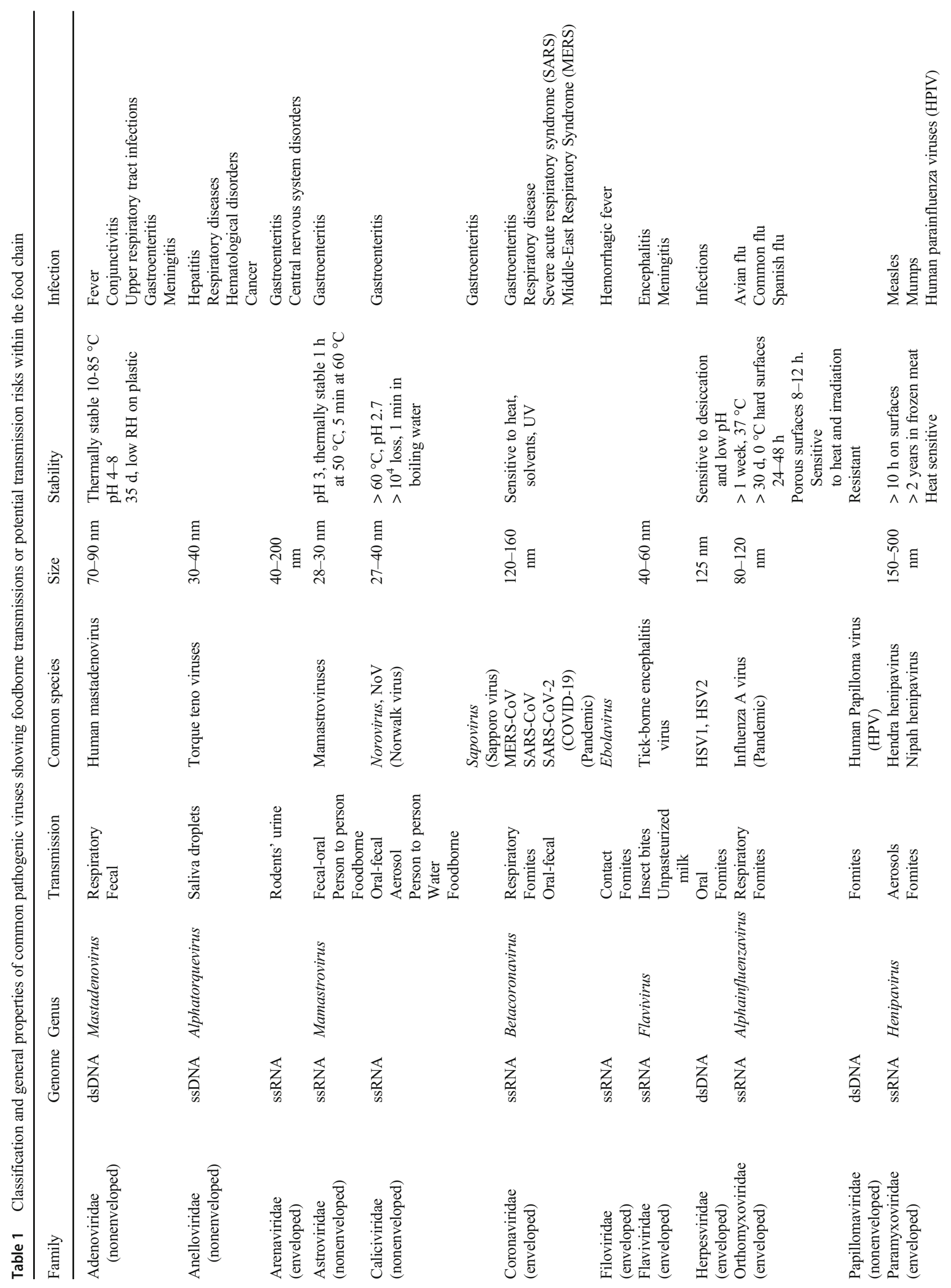




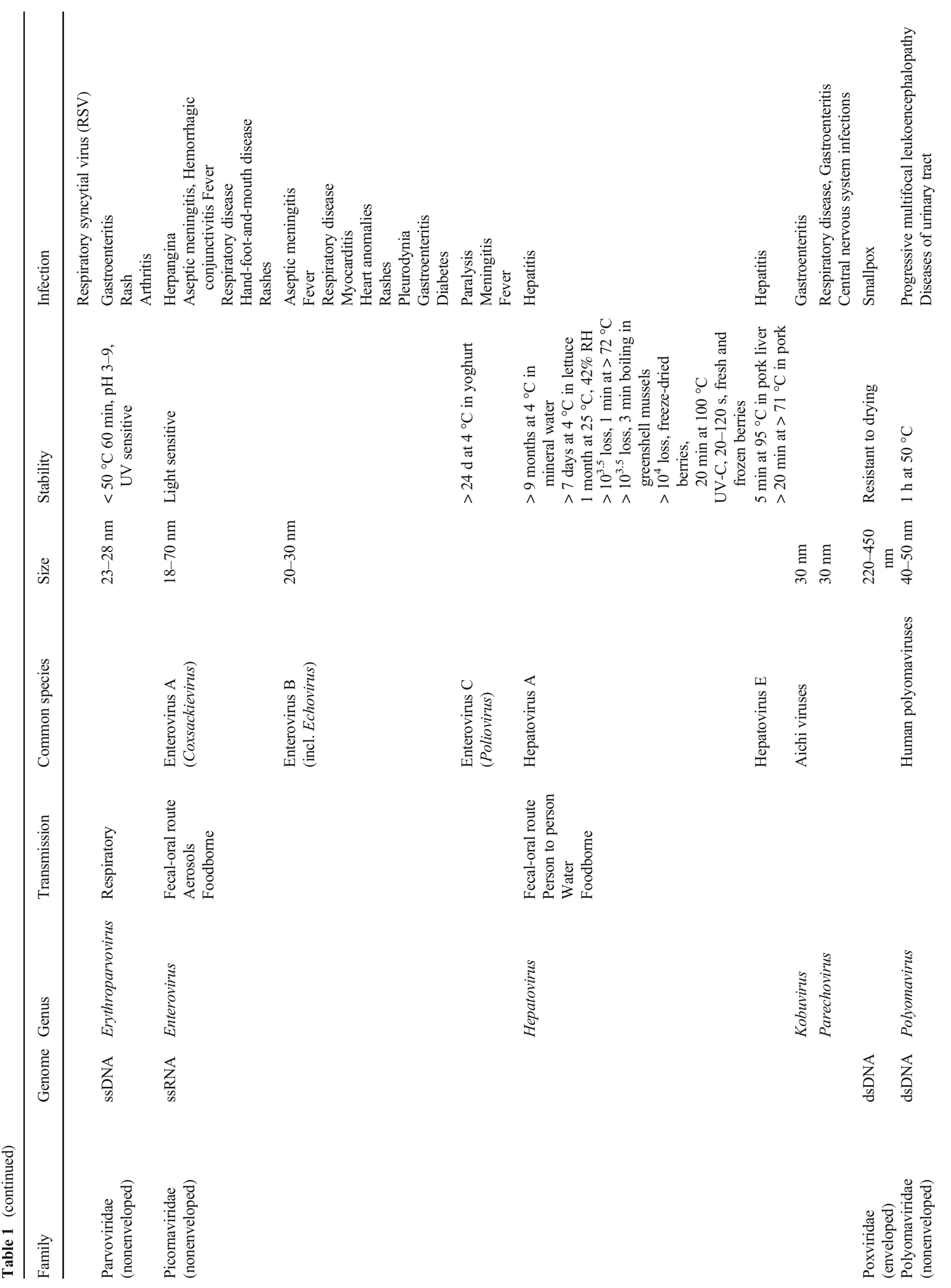




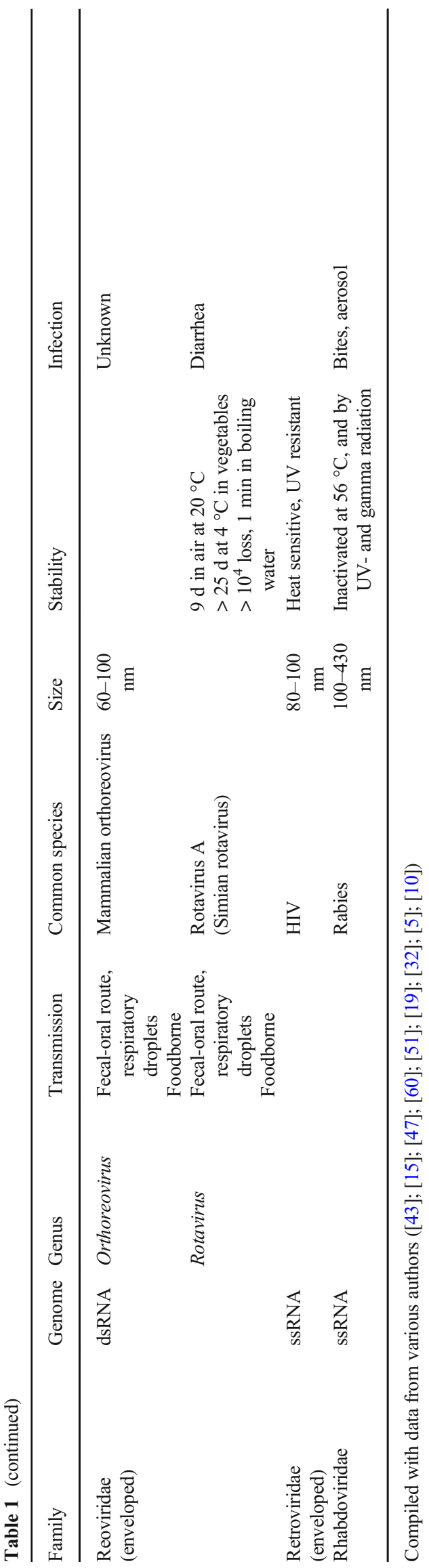

influenza viruses, including pandemic influenza A and coronaviruses, in food is also possible [40, 45]. According to Zuber et al. [60], enteric virions need to survive the enzymatic and extreme $\mathrm{pH}$ conditions of the gastric system which reflects their high resistance to many common food preservation and processing treatments. Likewise, enveloped virions of pathogenic viruses, e.g., influenza A virions have been shown to remain infective in frozen meat [15] and there is a possibility for survival of the new SARS-CoV-2 on meat surfaces [45]. Enveloped viruses are transmitted rather in fluids, respiratory droplets, blood, and tissue $[56,60]$ but their virions are more sensitive to environmental conditions and variations in humidity. Foodborne transmission of viruses is a potential risk in the case of enteroviruses but also other pathogenic viruses, and their spreading within the environment is wellrecognized [47]. A summary of common foodborne viral infections is given in Table 2 .

Enteric viruses can also be airborne, bloodborne (including vector-borne), or sexually transmitted.

\section{Enteric Viruses}

Traditionally microbial food safety is linked to gastroenteritis and bacteria transmitted directly from food. Loss of virions infectivity often relates to loss of capsid essential functions for introducing the viral genome to a host cell to initiate a viral infection [12]. Most foodborne virions have no envelope, and infectivity is retained well in conditions outside host cells [ $[15$, 25]. Many such virions demonstrate good resistance to extreme $\mathrm{pH}$ values (acid and alkaline), and virions may remain infective after drying, radiation, and other food preservation treatments [28, 32]. The essential parts of an infectious virus are the integrity of the genome and capsid protein at minimum [32]. Any treatment of food against pathogenic viruses must ensure sufficient loss of viral infectivity, i.e., numbers of infective virions need to decrease by several logarithmic cycles.

Enteric viruses are common in water and environment. Butot et al. [7] showed that viruses were not likely to contaminate bottled water. Their study showed that enteric viruses, HAV, HuNoV, and Rotavirus (RV) were adsorbed and remained on polyethylene terephthalate (PET) bottle surfaces and thereby retained infectivity at the PET surfaces even for $62 \mathrm{~d}$ at room temperature. Such attraction of viruses on hydrophobic surfaces emphasizes the importance of hydrophobic properties of nonenveloped virions to stability and loss of infectivity. Enteric viruses show interactions with many food components. According to Sánchez and Bosch [51], enteric viruses attach to foods by ionic and hydrophobic interactions, van den Waals forces, interaction with receptors (e.g., HuNoV attachment to carbohydrates), and uptake into bivalve mollusk and vegetable tissues. HAV has been shown to retain infectivity at $22{ }^{\circ} \mathrm{C}$ for $50 \mathrm{~d}$, and acidification is not a sufficient means to reduce HAV infectivity [50]. 
Table 2 Common virus infections transmitted within the food chain (Updated from [15])

\begin{tabular}{ll}
\hline Site of infection & Virus \\
\hline Neural tissue and nervous system & $\begin{array}{c}\text { Enterovirus, Nipah virus, Poliovirus, Parechovirus, } \\
\text { Tick-borne encephalitis virus }\end{array}$ \\
Respiratory system & Infuenza A, HPAI-H5N1, SARS-CoV, \\
& SARS-CoV-2 (Covid 19) \\
Liver & HAV, HEV \\
Intestinal system & NoV, HRV, Sapovirus, Astrovirus, \\
& Adenovirus, Aichi virus
\end{tabular}

\section{Influenza and Other Infections}

The SARS-CoV-2 outbreak in 2019/2020 has shown that viral transmissions are complex and foodborne transmission of Covid-19 is also a possibility [45]. Conversely, foodborne viral infections are not limited to viruses infecting human gastric track but rather to any infecting viruses, including common influenza virus (Table 1).

Virions in respiratory transmissions are often emitted from infected carriers as aerosols and droplets. Droplet nuclei in aerosols are below $10 \mu \mathrm{m}$ in size. Such droplets dropping from the height of $1.5 \mathrm{~m}$ take over $8 \mathrm{~min}$ while large droplets $>100 \mu \mathrm{m}$ are not inhaled and settle on surfaces within a few seconds (Weber and Stillianakis, 2008). Particles resulting from coughing, sneezing, and speaking vary over the range of 1 to $2000 \mu \mathrm{m}$ and interestingly correspond to droplet sizes in spray drying. Most particles are too large for inhalation (Weber and Stillianakis, 2008) and they settle on surfaces and cause droplet contamination in surroundings. A considerable number of up to 300,000 aerosol particles/cough over a size range of $0.35 \mu \mathrm{m}$ to $10 \mu \mathrm{m}$ may be expelled during coughing. The number of emitted particles is often higher for influenza patients than for healthy persons [35]. In some cases, small numbers between 1 and 100 virions may result in an infection [15] and an aerosol infection dose may be taken as 1000-2000 copies of the viral genome [41].

Employees are often an important source of direct and indirect virions transmissions. In manufacturing plants, aerosol particles are formed during coughing, sneezing, and speaking. Zayas et al. [58] found that during coughing of healthy individuals, $99 \%$ of droplets were less than $10 \mu \mathrm{m}$ in size. They also reported a large variation in droplet size and high emitters included an ex-smoker and a person older than 50 years. An outlier was involved in high intensity sports which may imply that virus spreading may become enhanced during activities with strong physical requirements, including such tasks in working environments. Although not statistically significant, older individuals seemed to emit larger droplets than younger persons [58].

\section{Stability of Virions}

Harper [20] found that a low temperature and low relative humidity enhanced survival of several viruses, although Poliovirus showed enhanced stability at a high humidity. The most important factors affecting the stability of virions in the aerosol state are temperature, $\mathrm{pH}$, relative humidity, water content, size of the aerosol particle, composition of the suspending medium, sunlight exposure, air quality, and virus type [51]. At high relative humidity, surface alteration of the virion has been reported, whereas at low relative humidity, virus inactivation appears to be mediated by the removal of structural water molecules. When dried on environmental fomites, HAV and Rotavirus are more resistant to inactivation than enteric Adenovirus, Astrovirus, and Poliovirus. The hydrophobic lipid bilayer is likely to provide strong hydrophobic properties to enveloped viruses. The envelope is often covered by glycoproteins which may also provide some hydrogen bonding capability. We assume that such structure enhances retention of water molecules in virions to support viral activity and it provides virions with protection against activity loss during release from host cells and spreading. Moreover, mannose-specific lectins of many plants, including garlic and leek, were found to show antiviral activity against coronavirus SARS-CoV [23]. Keyaerts et al. [23] presumed that such lectins interfered with the glycans of spike proteins during entry and release of virions at host cell membranes. In general, inactivation of virions is possible by damaging the genome, the protein coat, or the lipid bilayer and the associated glycoproteins [56]. Routes of inactivation according to Zhang et al. [59] are illustrated in Fig. 1.

\section{Thermal Stability}

Thermal processing provides an effective means for virus inactivation [28] although fat, protein, and sugars may improve stability of virions against thermal treatments $[9,14,50]$. Many studies have shown that temperatures above $50{ }^{\circ} \mathrm{C}$ are more effective in killing viruses than lower temperatures [2]. According to Sánchez [50] industrial blanching of vegetables at $100{ }^{\circ} \mathrm{C}$ for $120-180 \mathrm{~s}$ may reduce HAV infective virions by 


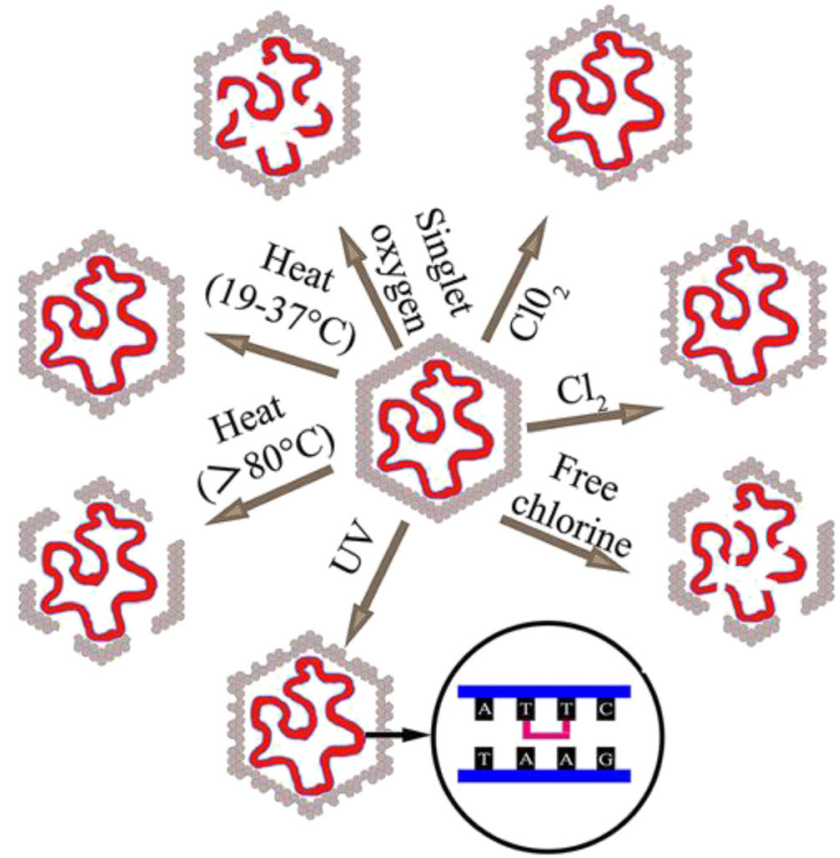

Fig. 1 Treatments leading to virions' inactivation as a result of damage on genome or capsid (Reproduced with permission from [59])

$>6 \log _{10}$ cycles. Conversely, virion inactivation occurs less rapidly in complex food matrices although infective virions are less resistant than the viral genome [2,9]. Interestingly virions seem to be less sensitive to thermal degradation than virus genomes both in simple (e.g., water) and complex (e.g., food) matrices. One may conclude that the complete virus structure provides protection to virus genome and loss of infectivity in food benefits from the shorter processing time of virion inactivation than may be suggested by genome degradation. Enteric viruses, such as HAV and parvovirus, as noted by Sánchez and Bosch [51], show higher thermal stability than most other viruses.

Despite challenges in determination of viability of virions and particularly in detecting virions infectivity, a number of studies have addressed virions survival in foods (e.g., [28, 50, $60])$. In general, many viruses cannot be cultured in vitro and studies of virus stability often use surrogates to achieve data on loss of infectivity $[39,51]$. According to Sánchez and Bosch [51], stability of viruses in foods is dependent on virus type, temperature, $\mathrm{pH}$, relative humidity, water content, sunlight exposure, and type of food. They also pointed out that the type of surface, for instance, the presence of crevices and hairlike projections in berries, may shield the viruses against environmental modifications and also the presence of natural antiviral compounds in the food itself may reduce risks of infections. Viruses are expected to occur in fresh foods primarily on surfaces, e.g., on surfaces of fresh and frozen berries, but inactivation occurs rapidly on hands. Butot et al. [10] found that UV-C light (200-280 nm) was effective in reducing HAV and Murine Norovirus (MNV) on fresh and frozen blueberries, raspberries, and strawberries. They, however, noted that the surface properties of the product as well as ice formation on surfaces may affect reduction of viruses. UV$\mathrm{C}$ light treatments are effective only on product surfaces. Virion inactivation on metal surfaces is highly dependent on metal type. A comprehensive research and statistical analysis of pre-2008 published data on influenza virus persistence in various environments was carried out by Irwin et al. [21]. They reported half-lives of virus concentrations in water, air, feces, and fomites at various temperatures as well as in aerosols varying in temperature and RH. Data were screened from 9760 relevant studies but only 19 studies provided sufficient details as most published data suffered a lack of virus concentrations at a minimum of two time points. Influenza virus H1N1 had the shortest half-life of $11.5 \mathrm{~min}$ in paper tissue transfer to hands at $28^{\circ} \mathrm{C}$ and $35-40 \%$ RH. Longest half-lives of 20.5 and $33.4 \mathrm{~h}$ were found for influenza virus H1N1 on eggshell and latex surfaces, respectively, at ambient temperature and humidity. An increase in temperature typically led to a shorter half-life.

The use of heat treatments has been most effective means for NoV inactivation [28, 32]. Alteration of capsid protein was considered as the main target of heat inactivation. Most foodborne viruses are inactivated during $>1 \mathrm{~min}$ heat treatment in boiling water but typical pasteurization temperatures around $>70^{\circ} \mathrm{C}$ may require up to $20 \mathrm{~min}$ for virus inactivation [5].

\section{Dehydration}

Bioactives require stability in food or pharmaceuticals and their retention, for example, in drying operations is of much interest. Spray drying involves aerosols and droplet sprays where bioactives often become protected. Bioactive and other components in formulations migrate during atomization and spray drying within a hydrophilic or hydrophobic phase or toward interfaces depending on their affinity [33]. Lowering of water activity often improves stability of bioactives and nutrients in foods. Dehydration of foods also seems to improve virion stability, and loss of infectivity may require substantially longer treatment times [5]. Moreover, atomization in spray drying results in a significant air-water interface area which may allow virions adhesion at droplet interfaces. Spray drying often uses sufficient pasteurization of liquid foods prior to atomization, as is required for virion inactivation and reduced infection risks.

Weber and Stilianakis [56] recognized the crucial role of water in inactivation of influenza viruses. Water is essential in maintaining the structure of the lipid bilayer of the envelope. According to Cliver [12], enteroviruses may become inactivated by drying, which is not true for HAV and HuNoV. Furthermore, enveloped viruses due to their hydrophobic properties tend to accumulate on droplet surfaces 
rather than remain inside droplets as was assumed by Marr et al. [38]. Interestingly, envelopes of virions (genome and capsid) contain $18-37 \%$ lipids by weight that originate from host cell lipids [56]. Although nonenveloped viruses rely less on lipid structures, their hydrophobic entry to target cells requires hydrophobic surface properties. Virions survival at various RH conditions in aerosols may vary although survival may increase at high RH and low temperature [56]. Both $\mathrm{RH}$ and absolute humidity ( $\mathrm{AH}$, mass of water in unit volume of air) have been suggested as key factors affecting virus stability [38]. Dehydration from aerosols and droplets at a low RH may increase virion stability, e.g., at room temperature where smallest $1-\mu \mathrm{m}$ droplets dehydrate in milliseconds and droplets up to $100-\mu \mathrm{m}$ in less than $1 \mathrm{~min}$ [56]. Droplets larger than $100 \mu \mathrm{m}$ are also likely to settle on surfaces from $1.5 \mathrm{~m}$ height in $5 \mathrm{~s}$ [38] where subsequent dehydration may become considerably delayed. However, the equilibrium water content of emitted particles in aerosols approach the equilibrium vapor pressure of water in the surrounding air, and the final droplet size and water content become dependent on droplet composition and RH [38]. Dehydration affects the droplet size and it seems that virus inactivation occurs more slowly than dehydration of aerosol particles to an equilibrium size and water vapor pressure [38]. One may also assume that aerosol droplets contain primarily proteins and $\mathrm{NaCl}$. Therefore, dehydration occurs rapidly to $0.75 \mathrm{a}_{\mathrm{w}}$ as $\mathrm{NaCl}$ approaches saturation concentration and other components have a minor effect on final droplet $\mathrm{a}_{\mathrm{w}}$ due to their large molecular size. At an equilibrium of $75 \% \mathrm{RH}\left(0.75 \mathrm{a}_{\mathrm{w}}\right)$, aerosol droplets retain approximately $40 \%$ of their initial diameter [38]. Obviously, the reduced size and water content have a significant effect on virions' gravitational settling, fate, and lifetime [38]. Marr et al. (2018) correctly noted that aerosol droplets became saturated during dehydration and subsequent crystallization of $\mathrm{NaCl}$ could enhance viral degradation. They also showed that the settling time of a $10-\mu \mathrm{m}$ particle during dehydration could change from approximately $8 \mathrm{~min}$ up to $4 \mathrm{~h}$ as a result of decreasing particle diameter. Interestingly, Marr et al. [38] concluded that temperature and RH were the most important parameters affecting virus stability. That is because temperature as an intrinsic factor was seen to control inactivation of viral macromolecules while $\mathrm{RH}$ was claimed to be an extrinsic factor controlling evaporation. It is, however, important to note that dehydration controls water activity and the physicochemical properties of both droplet and viral components. Indeed, Lin and Marr [34] reported that virion inactivation at intermediate $55 \% \mathrm{RH}$ levels was a result of solute concentration-induced damages to virions structure. They also noted that an intermediate-RH peak in virion inactivation occurred both in enveloped and nonenveloped structures. Such high sensitivity of virions to inactivation at intermediate $\mathrm{RH}$ levels over 40 to $85 \%$ RH $[34,46]$ suggests that RH control during dehydration may be used to maximize virions' inactivation during dehydration. On the other hand, thermal processing prior to liquid dehydration in food manufacturing is often sufficient to reduce risks of foodborne infections. Spontaneous rapid dehydration of aerosols at food manufacturing sites may retain virions' infectivity, and contamination from aerosols and droplets remains as a risk for food chain-related infections.

Low temperature drying can provide a high retention of sensory and nutritional food quality, but such food treatments also mean low inactivation levels of enteric viruses. Butot et al. [9] found that heating for $20 \mathrm{~min}$ at $120^{\circ} \mathrm{C}$ was required to inactivate $\mathrm{HAV}$ in freeze-dried berries. Obviously, such harsh treatment results in loss of the superior sensory quality and flavor retained during freeze-drying to dried products. HAV has been reported to show higher rate of decay at $80 \%$ $\mathrm{RH}$ than at $25 \% \mathrm{RH}$ on nonporous surfaces during $4 \mathrm{~h}$ at $20^{\circ} \mathrm{C}$ while survival can be higher at $90 \% \mathrm{RH}$ than at $50 \% \mathrm{RH}$ during $60 \mathrm{~d}$ at $20^{\circ} \mathrm{C}$ [32]. Survival of viruses seems to depend on species and types of surfaces besides storage $\mathrm{RH}$. $\mathrm{NaCl}$ concentrations of $\geq 10 \%$ could be used for inactivation of $\mathrm{HuNoV}$ and HAV in traditional Korean foods [42]. Enteric viruses, however, can be assumed to retain infectivity in dehydration of fruits and vegetables [50], and data on HAV infections have confirmed that many viruses retain infectiousness in drying [51]. There is also some evidence that glassy structures form in dehydration of aerosols and droplets which may contribute to virion inactivation due to reduced rate of drying at intermediate $\mathrm{RH}$ conditions, but enhanced retention of infectivity at low RH conditions $[34,55]$.

\section{Low Temperatures}

A decrease in temperature often reduces rates of chemical and biological changes, which may result in increased stability of virions. Furthermore, conformational changes of macromolecules, solidification of lipid components, and other physicochemical properties of viral components may affect increased virion stability at decreasing temperatures [44], although differences in stability mechanisms of enveloped and nonenveloped structures are likely. Chilled temperatures (2-11 ${ }^{\circ} \mathrm{C}$ ) during food storage in most studies have stabilized enteric viruses for a period exceeding product shelf life [51]. That is often a period of 30 days or longer. Thermal and environmental factors affecting virion stability are summarized in Table 3 .

Lipids in influenza virions appear solid at and below $4{ }^{\circ} \mathrm{C}$ while liquid state of lipids dominates above $40^{\circ} \mathrm{C}$ [44]. Chilling of contaminated foods seems to improve virion stability [31, 40]. Mullis et al. [40] found that a bovine coronavirus could retain infectivity on lettuce surfaces with a D-value of 5-6 days at $4{ }^{\circ} \mathrm{C}$. Virions showed a higher resistance with a $\mathrm{D}$-value of 14 days in a fecal suspension at the same conditions. Mullis et al. [40] suggested that dehydration on the lettuce surfaces could reduce infectivity. The findings of Mullis et al. [40] showed that 
Table 3 Structural and environmental factors affecting virion stability

\begin{tabular}{lllll}
\hline $\begin{array}{l}\text { Food } \\
\text { structure }^{\mathrm{a}}\end{array}$ & Biological & Chemical & Environmental & Physical \\
\hline Liquid & Natural antiviral compounds & Organic matter & Sunlight (UV & Temperature \\
Solid & Enzymes (proteases, & Antiviral chemicals & light) & Pressure \\
Semisolid & nucleases) & $\mathrm{pH}$ & Humidity (RH) & \\
Water & Microbial inactivation & Salinity & Temperature & \\
content & Biofilms stabilization & Ammonia (virucidal) & & \\
& Protozoal predation & Ions (Ag, Cu, Pt, Rh, & \\
& Virus strain & etc.) & \\
& & & & \\
\end{tabular}

a Food composition, temperature, and water content-dependent

Destabilizing factors are given as biological, chemical, environmental, and physical factor (After [51]) enveloped corona viruses may retain infectivity on food surfaces for a sufficiently long period of time to result in transmission and infection in humans. Marr et al. [38] noted that $\mathrm{pH}$ effect on thermal stability at temperatures below and above 50 ${ }^{\circ} \mathrm{C}$ suggested that temperature affected influenza virus stability at a molecular level. Such conclusion also implied that differences in temperature could alter virus degradation mechanisms and kinetics.

Freezing was not found by Butot et al. [8] to reduce viability of a number of viruses. Several studies have confirmed stability and retention of infectivity of virions during frozen storage of foods, particularly in frozen berries and shellfish [50, 51]. Sánchez and Bosch [51] concluded that freezing does not ensure an adequate reduction of enteric viruses if present in foods. On the other hand, there are variations in virus survival in foods depending on food composition. A higher decay rate has been found in blueberries, raspberries, and strawberries which was assumed to result from a lower $\mathrm{pH}$ [8]. However, one also needs to take into account the extent of freezing which depends on food composition (e.g., [48]). The extent of food freezing and virion stability at various frozen storage conditions has not been considered in studies addressing stability of virions at low temperatures. Berries are well known to have a higher unfrozen water content because of their high content of small sugars. On the other hand, virions may be found on product surfaces, but leaking of cellular fluids with sugars may affect the extent of freezing and virion stability during frozen storage. The survival of HAV and virions of other enteric viruses in frozen foods suggest that virions need to be inactivated prior to freezing to ensure food safety even after long frozen storage periods. Freezing and frozen storage in general seem ineffective in killing viruses [60].

\section{Water Activity}

Water activity, $\mathrm{a}_{\mathrm{w}}$, is a well-recognized parameter in understanding food stability, but $\mathrm{a}_{\mathrm{w}}$ is not often used as a virus stability parameter. Virions need no nutrients and virions have shown good stability in water. Enteric viruses may survive several months in water and high $\mathrm{a}_{\mathrm{w}}$ foods, such as yoghurt and cheese [49]. As enteric viruses in water were found to accumulate at PET surfaces [7], it suggested some hydrophobic interactions of nonencapsulated virions and virions' affinity to hydrophobic surfaces. Cook et al. [13] produced a comprehensive review on effects of heat, $\mathrm{pH}$, and water activity on the survival of HAV and HEV (Hepatitis E) viruses in food. Their review, however, covered the effects of RH on virus stability rather than $\mathrm{a}_{\mathrm{w}}$ of foods. It should be noted that most studies of effects of water on virion stability have observed the environmental $\mathrm{RH}$ rather than the equilibrium water vapor pressure, i.e., $\mathrm{a}_{\mathrm{w}}$, of the viral material. According to Sánchez and Bosch [51], surface alteration of virions at high RH and loss of structural water molecules at low RH contribute to virus inactivation. At high $\mathrm{RH}$ conditions, water may protect nonenveloped viruses in aerosols while enveloped viruses often exhibit improved stability at low RH [51]. Lin and Marr [34] reported that the high dose of solutes at intermediate $\mathrm{RH}$ conditions decreased dehydration as well as led to a higher level of virion inactivation.

Food materials often carry viral material on surfaces rather than as a contamination inside food. Some virions of enteric viruses may contaminate food and their infectivity can become dependent on $\mathrm{a}_{\mathrm{w}}$. That is, the water vapor pressure of the virion can be assumed to be at equilibrium with the vapor pressure of water within the food. Surprisingly, a small number of studies have reported the effects of RH in closed containers on virus survival. Stine et al. [53] found that HAV and feline calivirus (FCV) retained activity well at low RH conditions (mean RH 45-48\%). On the other hand, virions were more resistant in a complex food matrix than in water or simple solutions [2]. Indeed, a few studies have followed stability of HuNoV surrogates and HAV in real food materials. Data of Bozkurt et al. [6] and Lee et al. [30] confirmed enhanced retention of virus infectivity on wooden surfaces and real foods. Virions tend to show higher sensitivity to water and temperature at intermediate $\mathrm{RH}$ conditions. Prussin et al. [46] showed that infectivity of bacteriophage Phi6 (surrogate for influenza virus and other enveloped viruses) decreased 
significantly with increasing temperature over the range of 14 to $37^{\circ} \mathrm{C}$ and 40 to $85 \% \mathrm{RH}$.

Sánchez and Bosch [51] considered water as a medium that facilitated transmissions, but dehydration reduced such function. Enteric viruses have been shown to be resistant against dehydration and they may remain infectious several months in dried food or feces [13]. Kim et al. [24] stored HAV, MNV (HuNoV surrogate), and MS2 Bacteriophage over a range of $\mathrm{RH}(39,50$, and $70 \% \mathrm{RH})$ and temperatures $(15,25,32$, and $40{ }^{\circ} \mathrm{C}$ ) on stainless steel or coated wooden surfaces. They found that virion inactivation increased with temperature at all RH, and inactivation was significantly more rapid on stainless steel than on coated wood. Kim et al. [24] considered more rapid dehydration as a possibility for the difference although they noted that virus inactivation was also dependent on the type of the metal surface. One may note that significant differences in thermal conductivity, water condensation, and $\mathrm{a}_{\mathrm{w}}$ of the surface material can have an effect on loss of virus activity during storage. Furthermore, it is likely that wood approached the $\mathrm{a}_{\mathrm{w}}$ corresponding to equilibrium relative humidity (ERH) differently from stainless steel or other metals. Metals, indeed, may exhibit surface condensation which can increase local and thereby $\mathrm{a}_{\mathrm{w}}$ of virions. Other metals, such as copper, may also contain metal ions which may accelerate chemical reactions and physicochemical changes, including oxidation. All viruses studied by Kim et al. [24] showed retarded inactivation at $30 \% \mathrm{RH}$ on both surface materials. Casanova et al. [11] in their study of effects of RH on SARS-CoV surrogates considered the Maillard reaction as one possible reason to explain their finding of more rapid viral inactivation at $50 \% \mathrm{RH}$ than at 20 or $80 \% \mathrm{RH}$. They, however, stored viruses suspended in cell culture media dispensed as $10-\mu \mathrm{L}$ droplets on stainless steel surfaces. Obviously, dehydration and oxidation which may accelerate on metal surfaces were also considered as factors affecting loss of virions activity. The high level of virion inactivation at intermediate $\mathrm{RH}$ conditions [34] suggested that virions' infectivity is likely to reduce rapidly on intermediate moisture foods.

Relative humidity has an impact on virus survival in aerosols and droplets, as RH affects rates of dehydration of droplets containing virions. The study of Casanova et al. [11] used two enveloped coronaviruses, transmissible gastroenteritis virus, TGEV (Alphacoronavirus 1), and mouse hepatitis virus, MHV (Murine coronavirus) on stainless steel surfaces at 4 and $20{ }^{\circ} \mathrm{C}$ and 20,50 , and $80 \%$ RH. Such conditions were relevant for understanding virus stability in biological material at food manufacturing and handling facilities as well as effects of $\mathrm{a}_{\mathrm{w}}$ on virions. According to Marr et al. [38], stability of influenza viruses has shown either a decrease in stability with increasing RH or U-shaped relationship showing lowest stability at intermediate RH conditions. One may also assume that the hydrophobic lipids in enveloped viruses enhance virions' sensitivity to organic solvents and the envelope may have an impact on retention of infectivity at various $\mathrm{a}_{\mathrm{w}}$ conditions as well as affinity to varyingly electrostatic as well as hydrophobic or hydrophilic surfaces [27].

Casanova et al. [11] showed a significant retention of MHV and TGEV infectivity at 20\% RH (Fig. 2). Although D-values were $>12$ days at 4 and $20^{\circ} \mathrm{C}$ and $20 \% \mathrm{RH}$, more rapid loss of infectivity occurred at $50 \% \mathrm{RH}$ than at $80 \% \mathrm{RH}$ at $4{ }^{\circ} \mathrm{C}$ for MHV. A trend of D-values decrease with increasing temperature and RH was observed. D-values of $2-3 \mathrm{~h}$ at $40{ }^{\circ} \mathrm{C}$ and $80 \% \mathrm{RH}$ suggested that large numbers of virions of pandemic viruses may remain on surfaces for a sufficiently long time for spreading and infections. D-values of 1 to 2 months at $20 \%$ $\mathrm{RH}$ and 6 to 10 days at RH of 50 and $80 \%$ at $4{ }^{\circ} \mathrm{C}$ suggested that cold temperatures in food manufacturing and storage facilities can significantly enhance viral transmissions. Furthermore, virions may retain activity on contaminated food packages in cold distribution chains. The high rates of infections of the new Covid-19 at meat plants in several countries could be explain with the retention of infective virions at low temperature and high RH conditions. It should be noted that virions of these enveloped viruses are unlikely to exist inside food materials, as contamination is limited to aerosols, droplets, and surfaces.

\section{Inactivation and Inactivation Kinetics}

Inactivation of viruses involves degradation of genomes and inactivation of virions. Most studies have addressed degradation of genomes primarily using surrogates as detection of pathogenic viruses presents a number of analytical and safety challenges [28, 59].

An early study of Bidawid et al. [3] investigated inactivation of HAV in milk and cream. Inactivation was determined in skim milk ( $0 \%$ fat), homogenized milk ( $3.5 \%$ fat), and cream (18\% fat). Inactivation was followed at $65,67,69,71$, $73,75,80$, and $85^{\circ} \mathrm{C}$, but $5 \log _{10}$ reduction in titer at $85^{\circ} \mathrm{C}$ occurred within $0.5 \mathrm{~min}$. Their data up to $80^{\circ} \mathrm{C}$ showed that HAV inactivation occurred more rapidly in skim milk than in fat-containing products. There are no studies on effects of food structure on virus inactivation, but it seems that dispersed particles provide a hydrophilic-hydrophobic interface for adhesion of viruses. Foodborne virions seem to adhere on surfaces in food structures and it is expected that surfaces may enhance their stability. Moreover, virions accumulate on surfaces during transmissions and they also need surface attraction during adhesion on outer target cell membranes to cause a subsequent infection. Enveloped virions are often found on water-air interfaces $[11,56]$. Nonenveloped enteric viruses migrated on hydrophobic walls of PET water bottles [7], but information on nonencapsulated virions' assembly in dispersions is limited. 

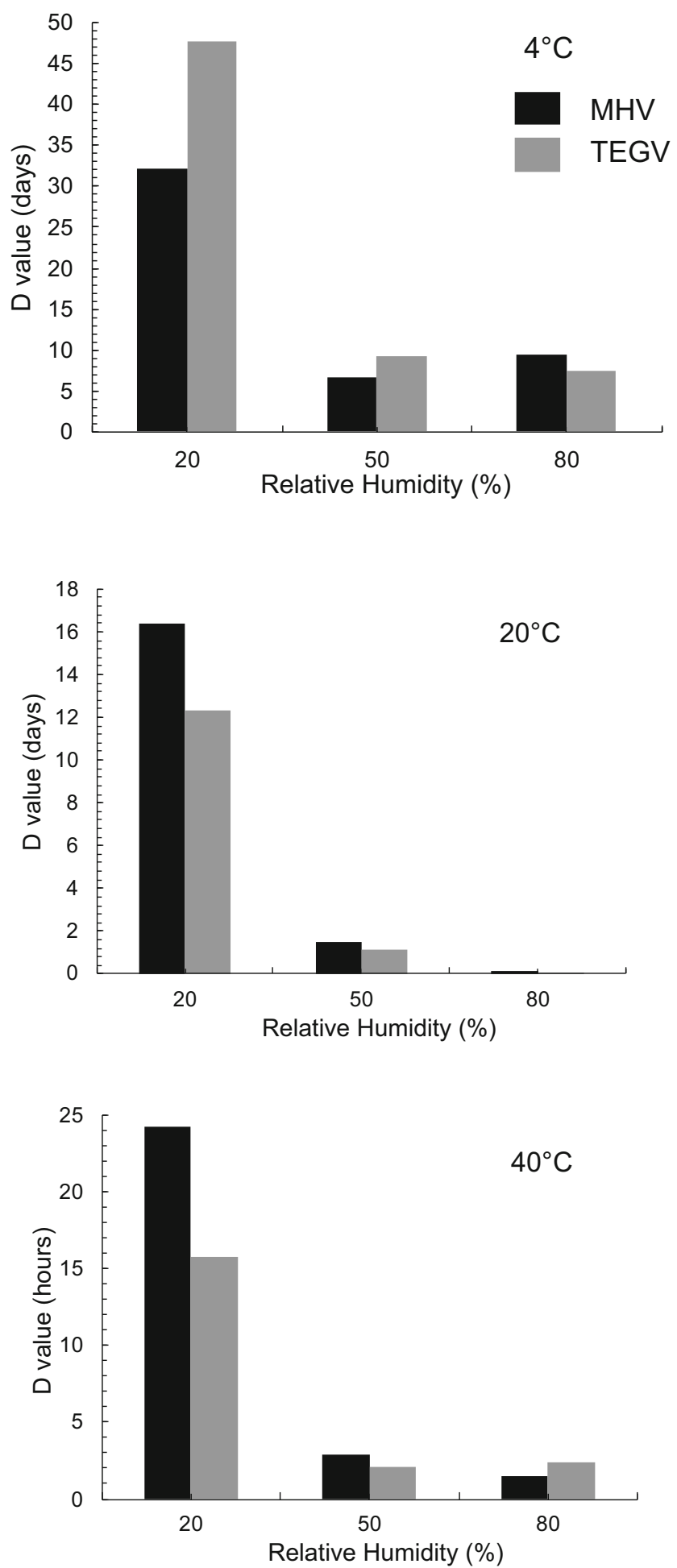

Fig. 2 Effect of temperature and relative humidity (RH) on enveloped mouse hepatitis virus (MHV) and transmissible gastroenteritis virus (TGEV) inactivation on stainless steel surface, as derived from data of Casanova et al. [11]

An Arrhenius plot of reported inactivation kinetics data of Bidawid et al. [3] is shown in Fig. 3. The results of Bidawid et al. [3] suggested that the activation energy,

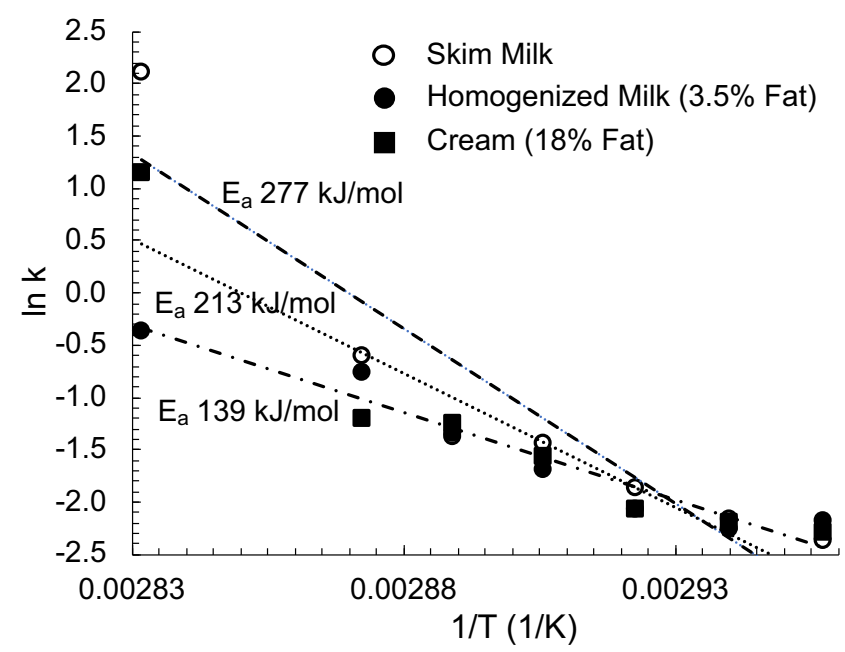

Fig. 3 An Arrhenius plot for HAV inactivation in skim milk, homogenized $3.5 \%$ fat milk, and $18 \%$ fat cream, as derived from data of Bidawid et al. [3]

$\mathrm{E}_{\mathrm{a}}$, was fairly similar around $140 \mathrm{~kJ} / \mathrm{mol}$ for all dairy products over the temperature range from 65 to $75{ }^{\circ} \mathrm{C}$. Above $75{ }^{\circ} \mathrm{C} \mathrm{E}_{\mathrm{a}}$ for skim milk showed a strong nonlinearity increasing $E_{a}$ to around $1500 \mathrm{~kJ} / \mathrm{mol}$ suggesting a change in inactivation mechanism. The inactivation of HAV occurred significantly more rapidly in skim milk than in homogenized $3.5 \%$ fat milk. Inactivation was also more rapid in the $18 \%$ fat cream. Such difference may have resulted from homogenization as the overall interface area may be assumed to be larger in the homogenized 3.5\% milk than in cream. The change in activation energy above $75{ }^{\circ} \mathrm{C}$ suggested that rapid denaturation of capsid proteins resulted in rapid HAV inactivation [32]. Cliver [12] noted that high temperatures of $95^{\circ} \mathrm{C}$ and above were detrimental to capsids of virions.

Bertrand et al. [2] analyzed kinetic data of thermal genome degradation or viral inactivation summarizing findings published in 73 original papers. They applied firstorder reaction kinetics to the data, i.e., viral inactivation or genome degradation was assumed to follow the relationship of equation (1). The Weibull model was reported to fit better to inactivation kinetics data of enteric viruses [6]. Lee et al. [30] studied HAV and HuNoV surrogates (murine norovirus, MNV, and bacteriophage, MS2) loss kinetics in digestive glands of oysters, and surface of cut, fresh peppers. They used "virus survival" models to assess kinetic data obtained during incubation at $4,15,25$, and 40 ${ }^{\circ} \mathrm{C}$ at both 50 and $70 \%$ RH. A linear model (2), Weibull distribution model (3), and a biphasic model (4) were fitted to virus inactivation data. The temperature range covered by Lee et al. [30] found little variation in virus inactivation at the two different RH conditions. They reported less rapid virus inactivation in oysters than in peppers. The biphasic model fitted well to experimental data. 
$\frac{C_{\mathrm{t}}}{C_{0}}=e^{-\mathrm{kt}}$

$\log _{10} \frac{N_{\mathrm{t}}}{N_{0}}=-\frac{t}{D}$

$\log _{10} \frac{N_{\mathrm{t}}}{N_{0}}=-b t^{\mathrm{n}}$

$\log _{10} \frac{N_{\mathrm{t}}}{N_{0}}=\log _{10}\left(\frac{2 \mathrm{f}}{1+e^{\mathrm{b}_{1} \mathrm{t}}}+\frac{2(1-\mathrm{f})}{1+e^{\mathrm{b}_{2} \mathrm{t}}}\right)$

where $t$ is time, $C_{\mathrm{t}}$ is concentration at time $t, C_{0}$ is concentration at $t=0 . N_{\mathrm{t}}$ and $N_{0}$ correspond to $C_{\mathrm{t}}$ and $C_{0}$ but referring to the number of viruses, $D$ is decimal reduction time, $b$ and $n$ are scaling parameters, $f$ is first fraction surviving, and $b_{1}$ and $b_{2}$ are slopes of the first and second phases, respectively.

Bertrand et al. [2] used time for first $\log _{10}$ reduction (TFL value) of genome degradation or viral inactivation as a universal kinetic criterion. TFL value was analogous to D-value, i.e., decimal reduction time, commonly used in thermal processing, but limited to the first $\log _{10}$ decrease. The TFL value represented a larger rate constant than would be found for subsequent D-values. The Weibull model could provide a corresponding applicability. The Weibull model takes into account an initial concavity that was shown by the decrease in viral concentration. It appeared that $\log _{10}$ TFL decreased linearly with increasing temperature, but the relationship showed a steeper slope for data above $50{ }^{\circ} \mathrm{C}$ than below 50 ${ }^{\circ} \mathrm{C}$. Although their data covered enteric, foodborne viruses and bacteriophages, they provided an overview of viral loss kinetics at normal ambient and common food processing temperatures.

Figure 4 shows TFL values at $72{ }^{\circ} \mathrm{C}$ derived from the data of Bertrand et al. [2] for common enteric viruses. Bertrand et al. [2] classified materials as "simple" and "complex" matrices, which represented high water content and $\mathrm{a}_{\mathrm{w}}$ materials, such as water or a simple solution, or a more complex, real food type materials, respectively. Such classification followed common findings that virions' inactivation occurs more rapidly in water than in food materials. These findings agreed with the data of Bidawid et al. [3] for dairy liquids. The TFL at $72{ }^{\circ} \mathrm{C}$ was longer than was suggested by the data of Bidawid et al. [3] for HAV in milk and cream. An interesting finding was that $\log _{10}$ (TFL) had similar slope values for all virions, but only the slopes below and above $50{ }^{\circ} \mathrm{C}$ were different. Another variation was the intercept, $\alpha_{0}$, at $T=0{ }^{\circ} \mathrm{C}$. In other words, the effect of temperature on the $\log _{10}$ (TFL) was not virus specific while each virus had an individual $\alpha_{0}$ and corresponding $\log _{10}$ (TFL). Such temperature dependence supported the earlier assumption of Liu [36] suggesting that

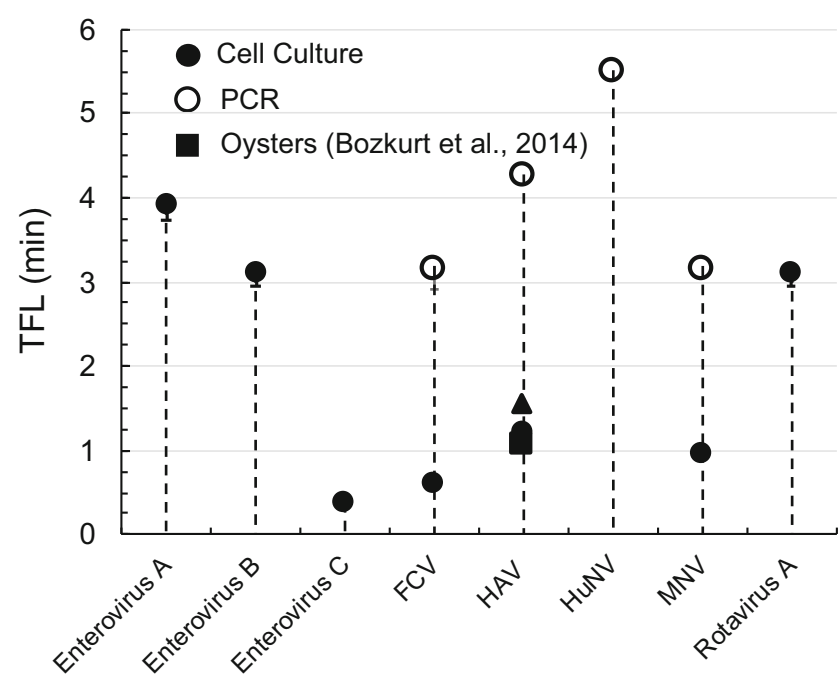

Fig. 4 Time to first logarithmic decrease (TFL or first D-value) for genome degradation (PCR method) or loss of infectivity (Cell Culture) for main enteric virus species causing gastroenteric infections at $72{ }^{\circ} \mathrm{C}$ as derived from kinetic data of Bertrand et al. [2] for complex materials. Dvalue for HAV in oysters from Bozkurt et al. [6] is shown for comparison

virion inactivation followed thermal kinetics of chemical degradation reactions.

Bertrand et al. [2] concluded that the universal temperature dependence allowed a "worst case" virus to be selected as the most persistent risk for evaluation of thermal inactivation. One should note that such worst case needs to be validated for being sufficient to inactivate the most resistant and infective virions. The authors did not consider infective doses, which can vary significantly among virus infections. Sánchez [50] in her review concluded that pasteurization at $63{ }^{\circ} \mathrm{C}$ for $30 \mathrm{~min}$ or at $70{ }^{\circ} \mathrm{C}$ for 2 min seemed to be more effective against HAV inactivation than short-time pasteurization $\left(71.7^{\circ} \mathrm{C}\right.$ for $\left.15-20 \mathrm{~s}\right)$, but such thermal treatments were not sufficient for complete virion inactivation. She also noted that normal cooking of shellfish was not sufficient to inactivate HAV unless the shellfish internal temperature reached 85-90 ${ }^{\circ} \mathrm{C}$ for $1.5 \mathrm{~min}$ which compromised sensory quality.

The results of Bertrand et al. [2] indicated that the TFL value at temperatures $<50{ }^{\circ} \mathrm{C}$ was several days and extended to several months at $0{ }^{\circ} \mathrm{C}$ (Fig. 5). Such levels of genome degradation or virion inactivation suggested that enteric viruses often remained infective in fresh foods until consumed or to the end of product shelf life in agreement with numerous studies on stability of enteric viruses in foods [51]. That is washing and other forms of cleaning are essential in reducing infection risks. A further support on virus infectivity in contaminated foods is seen from the fairly low activation energies which apply to virion inactivation below $50{ }^{\circ} \mathrm{C}$ (Fig. 6). Conversely, thermal treatment at temperatures $>50^{\circ} \mathrm{C}$, preferably $>95^{\circ} \mathrm{C}$, are required for efficient virion inactivation. 


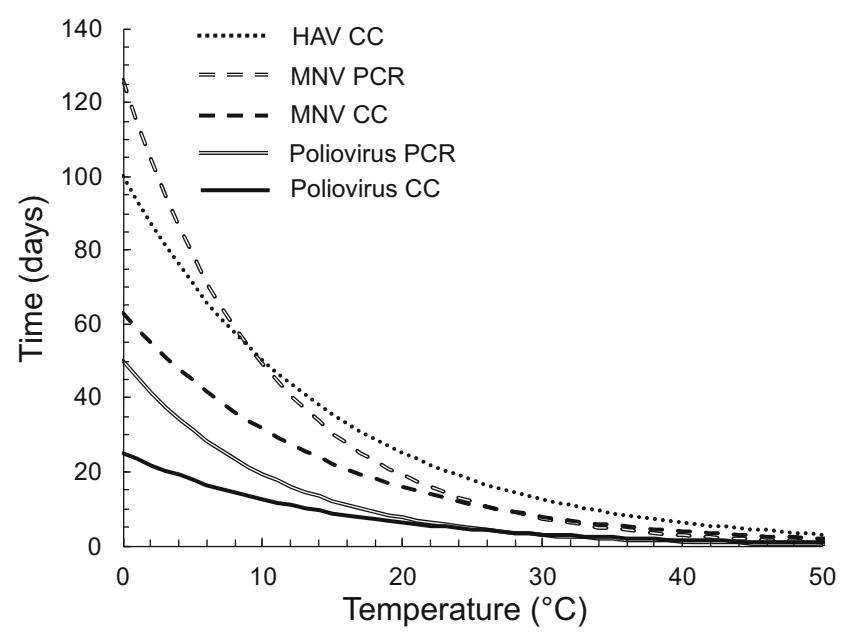

Fig. 5 Time to first $\log _{10}$ of genetic degradation (PCR) or virus inactivation (Cell Culture, CC) in a complex material as derived from data of Bertrand et al. [2]

Even then the "worst case" treatment for TFL can be up to $2 \mathrm{~h}$, although for most virions D-value (TFL) for inactivation could be less than a few seconds.

Food-related studies of viruses are limited to potential foodborne transmissions and illnesses spreading in the food chain. Studies involving highly infective pandemic viruses have significant challenges in laboratory experiments but could be valuable for understanding possible other than foodborne spreading routes. Moreover, data for enveloped viruses may differ from mainly nonenveloped, gastric viruses. Although Casanova et al. [11] dispensed virions in cell culture media on stainless steel surfaces, they used saturated salt solutions and controlled temperature conditions to maintain constant temperature and RH. Their data can be used to derive Dvalues and activation energies for coronaviruses. Such data are also important examples of effects of water and temperature on inactivation of enveloped pandemic viruses.

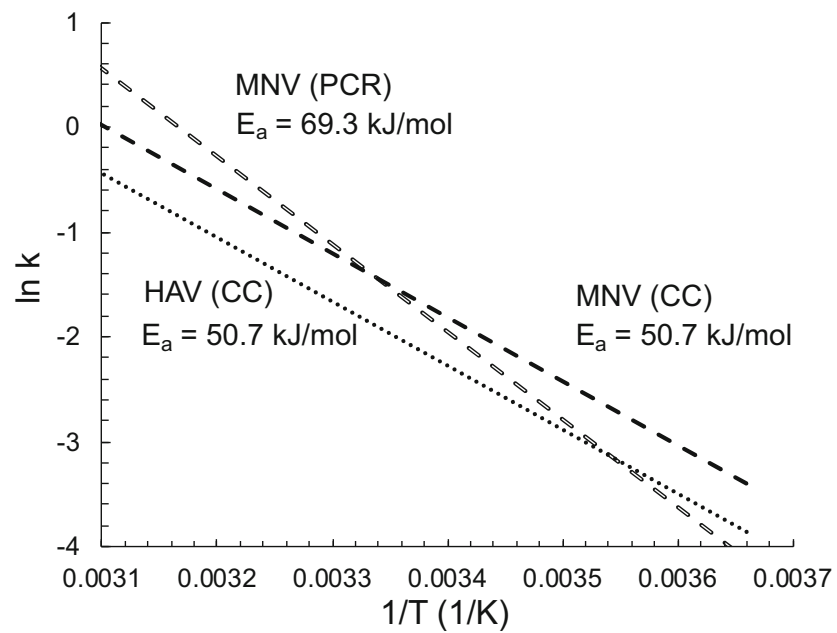

Fig. 6 Arrhenius plots for HAV virion inactivation as well as MNV genome degradation (PCR) and virion inactivation $(\mathrm{CC})$ at 0 to $50{ }^{\circ} \mathrm{C}$, as derived from data of Bertrand et al. [2]
The data of Casanova et al. [11] showed that relative humidity had only a minor effect on MHV and TGEV activation energy. As shown in Fig. 7, the activation energy at the higher RH conditions varied little between the two viruses, although TGEV seemed to have a larger difference at $80 \% \mathrm{RH}$. It should be noted that the data of Casanova et al. [11] similar to other studies of virion inactivation showed large variations and standard deviations. The data for both strains at $20 \%$ humidity suggested that inactivation mechanisms of virions at lower and higher temperatures were different and such variation was more pronounced at low RH (Fig. 7). One possible factor reducing activation energy below $20{ }^{\circ} \mathrm{C}$ is solidification of the lipid components of the envelope. Furthermore, dehydration of structural components of the virion may be expected to result in conformational changes in proteins and other component macromolecules. Unfortunately, there are no available data on the effect of cooling-reheating cycles on loss of infectivity of enveloped viruses to address lipid solidification and changes in macromolecular conformation. However, inactivation of virions at higher temperatures for the development and stability of vaccines is commonly addressed.

Thermal degradation may follow first-order kinetics, although non-linearity in plotting logarithmic concentration against time is often reported [6, 30, 57]. Liu et al. [36] considered denaturation of the SARS coronavirus as a temperature-dependent rate problem. Their analysis of kinetic data for SARS coronavirus inactivation showed a significant temperature dependence, particularly below 50 ${ }^{\circ} \mathrm{C}$. Accordingly, the exponential increase in virion stability suggested SARS coronavirus stability to extend over several days or weeks at low temperatures. The activation energy obtained was $93 \mathrm{~kJ} / \mathrm{mol}$ in fairly good agreement

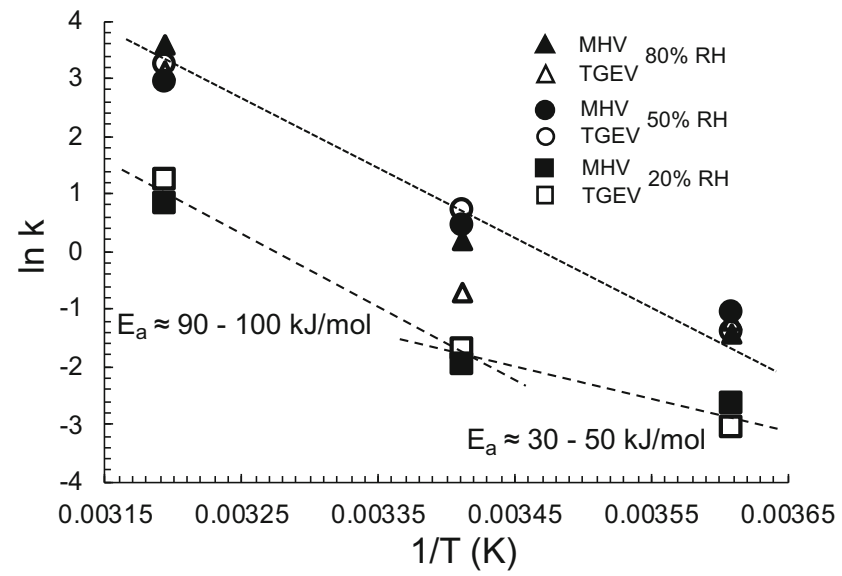

Fig. 7 Temperature dependence of first-order loss of infectivity of enveloped coronaviruses, transmissible gastroenteritis virus, TGEV (Alphacoronavirus 1), and mouse hepatitis virus, MHV (Murine coronavirus) at 20,50 , and $80 \%$ relative humidity calivirus ( $\mathrm{RH})$, as derived from data of Casanova et al. [11] 
with temperature dependence of inactivation of enteric viruses. Liu [36] estimated that SARS-CoV could have a lifetime of $16 \mathrm{~h}$ at $25{ }^{\circ} \mathrm{C}$ while at $0{ }^{\circ} \mathrm{C}$ SARS-CoV could remain infective over $20 \mathrm{~d}$. Conversely, inactivation of SARS-CoV at temperatures approaching $80{ }^{\circ} \mathrm{C}$ could occur within $3 \mathrm{~min}$ [36]. Madani et al. [37] reported an activation energy of $97.3 \mathrm{~kJ} / \mathrm{mol}$ for inactivation of a Flavivirus (Alkhumra hemorrhagic fever virus, AHFV) over a temperature range of 45 to $60{ }^{\circ} \mathrm{C}$ showing a corresponding activation energy for the loss of infectivity. According to Marr et al. [38], similarities in mechanisms of thermal degradation of influenza virus may apply over a range of systems, including aerosols, droplets, surfaces, and bulk culture medium.

Studies reporting kinetic data with temperature dependence of virus inactivation have often a limited temperature range below $50{ }^{\circ} \mathrm{C}$, and very little data are available on the impact of water content on thermal inactivation. This is particularly true for influenza and other enveloped viruses.

\section{Novel Processing}

Modified atmosphere technology or packaging (MAP) may significantly improve the shelf life of many fresh foods, but it may not inactivate HAV $[4,50]$ and perhaps neither other viruses when food grade and safe gases are used. MAP and other novel processing treatments, such as HPP, pulsed electric fields (PEF), pulsed light, cold plas$\mathrm{ma}$, or UV light, are used primarily for fresh or high $\mathrm{a}_{\mathrm{w}}$ foods. Both HPP [26, 32] and cold plasma [1, 29] may provide means for virion inactivation besides thermal processing. According to Li et al. [32], HPP could damage HuNoV capsid which explained virus inactivation.

HAV contamination is common in seafood, and a number of studies have reported effects of HPP or UV light treatment during shellfish depuration [17, 50]. Kingsley and co-workers as reviewed by Kingsley (2013) have investigated effects of HPP on various nonenveloped enteric viruses in foods. Kingsley (2013) noted that enteric viruses as nonencapsulated viruses need to become inactivated as a result of changes in protein conformation. That conclusion was made as enteric viruses have no lipid-specific component, and HPP is not effective in braking covalent bonds of nucleic acids. According to Sánchez [50], HPP treatments at $>400 \mathrm{MPa}$ are effective in HAV inactivation. UV-C light treatments or pulsed UV light have also reduced HAV contamination in fruits, vegetables, and other foods. As in other stability studies, virus inactivation in HPP and UV light treatments has been found to depend on the chemical surroundings of the viruses, i.e., food composition, $\mathrm{pH}$, etc. [50]. Studies of pulsed electric fields, ultrasound, and other emerging technologies' effects on viruses have been very limited. Irradiation using gamma rays is also possible, but a high dose of gamma rays is required even in aqueous suspensions to effectively degrade virions [12].

Novel processing technologies would be applicable pretreatments prior to thermal processing, freezing, dehydration, and other food preservation to ensure virus inactivation and ensure minimal losses in food quality. Moreover, combined processes in the control of foodborne infections may show more useful in reducing infection risks. On the other hand, refrigerated temperature in caliciviruses HPP treatment has been unexpectedly found to enhance loss of virion infectivity (Kingsley, 2013). HPP treatment parameters for virion inactivation also seem to vary substantially among various virus species.

\section{Conclusions}

Virions in food, water, and the environment are infective macromolecular bioparticles. Several nonenveloped, enteric viruses contaminate fresh products, but pathogenic enteric viruses have a high resistance against virion inactivation. Thermal processing exceeding common protein denaturation temperatures is often detrimental to genomic material and sufficiently efficient to reduce infective virion numbers and ensure food safety. Moreover, virions are structured to protect their genome outside infected cells. Loss of virus infectivity is a result of physicochemical changes and chemical reactions. Such changes and reactions include, for example, dehydration, hydrogen bonding, hydrophobic interactions, electrostatic changes, and molecular conformations. Consequently, virus inactivation needs to be considered in a similar context as loss of nutrients or bioactive substances. Virion inactivation, however, needs to take into account virion stability in aerosols and droplets besides survival in food and surfaces. Little is known on effects of water on virions' stability or loss of infectivity. Dehydration of virions in aerosols and droplets has similarities with spray drying but it may affect both virion stability and loss of infectivity. Kinetics of losses of virions infectivity suggest differences in inactivation mechanisms at lower temperatures below common pasteurization temperatures and higher temperatures applicable to pasteurization and thermal processing. Activation energies are little affected by virus strains which, however, show large differences in thermal processing needs. Novel food processing technologies provide additional means to control viral food safety. HPP and cold plasma treatment are examples of new technologies which may be used in food pretreatment without compromising food quality prior to subsequent food preservation. 


\section{References}

1. Bae S-C, Park SY, Choe W, Ha S-D (2015) Inactivation of murine norovirus-1 and hepatitis A virus on fresh meats by atmospheric pressure plasma jets. Food Res Int 76:342-347

2. Bertrand I, Schijven JF, Sánchez G, Wyn-Jones P, Ottoson J, Morin T, Muscillo M, Verani M, Nasser A, de Roda Husman AM, Myrmel M, Sellwood J, Cook N, Gantzer D (2012) The impact of temperature on the inactivation of enteric viruses in food and water: a review. J Appl Microbiol 112:1059-1074

3. Bidawid S, Farber JM, Sattar SA, Hayward S (2000) Heat inactivation of hepatitis A virus in dairy foods. J. Food Protection 63: $522-528$

4. Bidawid S, Farber JM, Sattar SA (2001) Survival of hepatitis A virus on modified atmosphere-packaged (MAP) lettuce. Food Microbiol 18:95-102. https://doi.org/10.1006/fmic.2000.0380

5. Bosch A, Gkogka E, Le Guyader S, Loisy-Hamon F, Lee A, van Lieshout L, Marthi B, Myrmel M, Sansom A, Schultz AC, Winkler A, Zuber S, Phister T (2018) Foodborne viruses: detection, risk assessment, and control options in food processing. Int J Food Microbiol 285:110-128

6. Bozkurt H, D'Souza DH, Davidson PM (2014) Determination of thermal inactivation kinetics of hepatitis A virus in blue mussel (Mytilus edulis) homogenate. Appl Environ Microbiol 80:31913197

7. Butot S, Putallaz T, Croquet C, Lamothe G, Meyer R, Joosten H, Sánchez G (2007) Attachment of enteric viruses to bottles. Appl Environm Microb 73:5104-5110

8. Butot S, Putallaz T, Sánchez G (2008) Effects of sanitation, freezing and frozen storage on enteric viruses in berries and herbs. Int J Food Microbiol 126(2008):30-35

9. Butot S, Putallaz T, Amoroso R, Sánchez G (2009) Inactivation of enteric viruses in minimally processed berries and herbs. Appl Environ Microbiol 75:4155-4161

10. Butot S, Cantergiani C, Moser M, Jean J, Lima A, Michot L, Putallaz T, Stroheker T, Zuber S (2018) UV-C inactivation of foodborne bacterial and viral pathogens and surrogates on fresh and frozen berries. Int J Food Microbiol 275:8-16

11. Casanova, L.M., Jeon, S., Rutala, W.A., Weber, D.J. and Sobsey, M.D. (2010) Effects of air temperature and relative humidity on coronavirus survival on surfaces. Appl. Environm. Microbiol. 76: 2712-2717. https://doi.org/10.1128/AEM.02291-09

12. Cliver DO (2009) Capsid and infectivity in virus detection. Food Environ Virol 1:123-128. https://doi.org/10.1007/s12560-0099020-y

13. Cook N, Bertrand I, Bosch A, Gantzer C, Maul A, Pinto R, van der Poel W, Stein J (2014) A critical review of the effect of heat, $\mathrm{pH}$ and water activity on the survival of hepatitis A and E viruses. FSA Project FS101074. Food Standards Agency, United Kingdom, p 98

14. Deboosere N, Legeay O, Caudrelier Y, Lange M (2004) Modelling effect of physical and chemical parameters on heat inactivation kinetics of hepatitis A virus in a fruit model system. Int J Food Microbiol 93:73-85

15. FAO and WHO (2008) Viruses in food: scientific advice to support risk management activities. Meeting Report. Microbiological Risk Assessment Series 13:1-79

16. Galanakis CM (2020) The food systems in the era of the coronavirus (COVID-19) pandemic crisis. Foods 2020(9):523. https://doi. org $/ 10.3390 /$ foods 9040523

17. Garcia LA, Nascimento MA, Barardi CRM (2015) Effect of UV light on the inactivation of recombinant human adenovirus and murine norovirus seeded in seawater in shellfish depuration tanks. Food Environ Virol 7:67-75. https://doi.org/10.1007/s12560-0149177-x
18. Gorbalenya AE, Krupovic M, Mushegian A, Kropinski AM, Siddell SG, Varsani A, Adams MJ, Davison AJ, Dutilh BE, Harrach B, Harrison RL, Junglen S, King AMQ, Knowles NJ, Lefkowitz EJ, Nibert ML, Rubino L, Sabanadzovic S, Sanfaçon H, Simmonds P, Walker PJ, Zerbini FM, Kuhn JH (2020) The new scope of virus taxonomy: partitioning the virosphere into 15 hierarchical ranks. Nat Microbiol 5:668-674

19. Greening GE, Cannon JL (2016) Human and animal viruses in food (including taxonomy of enteric viruses). In: Goyal SM, Cannon JL (eds) Viruses in Foods. Springer, Switzerland. https://doi.org/10. 1007/978-3-319-30723-7_2

20. Harper GJ (1961) Airborne micro-organisms: survival tests with four viurses. J Hyg Cambridge 59:479-486. https://doi.org/10. 1017/S0022172400039176

21. Irwin CK, Yoon KJ, Wang C, Hoff SJ, Zimmerman JJ, Denagamage T, O'Connor AM (2011) Using the systematic review methodology to evaluate factors that influence the persistence of influenza virus in environmental matrices. Appl Environ Microbiol 77:1049-1060

22. Jalava K (2020) First respiratory transmitted food borne outbreak? Int J Hyg Environ Health 226(2020):113490

23. Keyaerts E, Vijgen L, Pannecouque C, Van Damme E, Peumans W, Egberik H, Balzarini J, Van Ranst M (2007) Plant lectins are potent inhibitors of coronaviruses by interfering with two targets in the viral replication cycle. Antivir Res 75:179-187

24. Kim SJ, Si J, Lee JE, Ko GP (2012) Temperature and humidity influences on inactivation kinetics of enteric viruses on surfaces. Environ Sci Technol 46:13303-13310

25. King T, Cole M, Farber JM, Eisenbrand G, Zabaras D, Fox EM, Hill JP (2017) Food safety for food security: relationship between global megatrends and developments in food safety. Trends Food Sci Technol 68:160-175

26. Kingsley, D.H. (2013) High pressure processing and its application to the challenge of virus-contaminated foods. Food Environ Virol 5: 1-12. https://doi.org/10.1007/s12560-012-9094-9

27. Konda A, Prakash A, Moss GA, Schmoldt M, Grant GD, Guha S (2020) Aerosol filtration efficiency of common fabrics used in respiratory cloth masks. ACS Nano In press. https://doi.org/10.1021/ acsnano.0c03252

28. Koopmans M, Duizer E (2004) Foodborne viruses: an emerging problem. Int J Food Microbiol 90:23-41

29. Lacombe A, Niemira BA, Gurtler JB, Sites J, Byod G, Kingsley DH, Li X, Chen H (2019) Nonthermal inactivation of norovirus surrogates on blueberries using atmospheric cold plasma. Food Microbiol 63:1-5

30. Lee SJ, Si J, Yun HS, Ko GP (2015) Effect of temperature and relative humidity on the survival of foodborne viruses during food storage. Appl Environ Microbiol 81:2075-2081

31. Li, D., De Keuckelaere, A. and Uyttendaele, M. (2015) Fate of foodborne viruses in the "Farm to Fork" chain of fresh produce. Compr Rev Food Sci Food Safety 14: 755-770. https://doi.org/10. 1111/1541-4337.12163

32. Li D, Keuckelaere AD, Uyttendaele M (2017) Impact of food unit operations on virus loads in foods. In: In Quantitative Microbiology in Food Processing: Modeling the Microbial Ecology, Anderson de Souza Sant'Ana (ed). John Wiley \& Sons, New York

33. Lim ASL, Burdikova Z, Sheehan JJ, Roos YH (2016) Carotenoid stability in high total solid spray dried emulsions with gum Arabic layered interface and trehalose-WPI composites as wall materials. Innov Food Sci Emerg Technol 34:310-319. https://doi.org/10. 1016/j.ifset.2016.03.001

34. Lin K, Marr LC (2020) Humidity-dependent decay of viruses, but not bacteria, in aerosols and droplets follows disinfection kinetics. Environ Sci Technol 54:1024-1032. https://doi.org/10.1021/acs. est.9b04959 
35. Lindsley WG, Pearce TA, Hudnall JB, Davis KA, Davis SM, Fisher MA, Khakoo R, Palmer JE, Clark KE, Celik I, Coffey CC, Blachere FM, Beezhold DH (2012) Quantity and size distribution of coughgenerated aerosol particles produced by influenza patients during and after illness. J Occup Environ Hyg 9(7):443-449. https://doi. org/10.1080/15459624.2012.684582

36. Liu J (2004) A rate equation approach to model the denaturation or replication behavior of the SARS coronavirus. Forsch Ingenieurwes 68:227-238. https://doi.org/10.1007/s10010-004-0130-2

37. Madani TA, Abuelzein E-TME, Ahar EI, Al-Bar HMS (2014) Thermal inactivation of Alkhumra hemorrhagic fever virus. Arch Virol 159:2682-2691. https://doi.org/10.1007/s00705-014-2134-Z

38. Marr LC, Tang JW, van Mullekom J, Lakdawala SS (2019) Mechanistic insights into the effect of humidity on airborne influenza virus survival, transmission and incidence. J R Soc Interface 16:20180298. https://doi.org/10.1098/rsif.2018.0298

39. Miranda RC, Schaffner DW (2019) Virus risk in the food supply chain. Curr Opin Food Sci 30:43-48

40. Mullis L, Saif LJ, Zhang AY, Zhang X, Azevedo MSP (2012) Stability of bovine coronavirus on lettuce surfaces under household refrigeration conditions. Food Microbiol 30:180-186

41. Nikitin N, Petrova E, Trifonova E, Karpova O (2014) Influenza virus aerosols in the air and their infectiousness. Adv Virol 2014: 859090. https://doi.org/10.1155/2014/859090

42. Park, S.Y. and Ha, S.-D. 2014. Influence of $\mathrm{NaCl}$ on the inactivation of murine norovirus- 1 and hepatitis A virus in the Korean traditional salted oyster product "Eoriguljeot" during storage. Food Res Intl 62: 382-387. https://doi.org/10.1016/j.foodres.2014. 03.039

43. Pirtle EC, Beran GW (1991) Virus survival in the environment. Rev Sci Tech Off Int Epiz 10(3):733-748

44. Polozov I.V., Bezrukov L, Gawrisch K, Zimmerberg J (2008) Progressive ordering with decreasing temperature of the phospholipids of influenza virus. Nat Chem Biol 4:248-255. https://doi.org/ 10.1038/nchembio.77

45. Pressman P, Naidu AS, Clemens R (2020). Covid-19 and food Safety: Risk management and future considerations. Journals. lww.com/nutritionontodayonline. Accessed 24 May 2020

46. Prussin J, Schwake DO, Lin K, Gallagher DL, Buttling L, Marr LC (2018) Survival of the enveloped virus Phi6 in droplets as a function of relative humidity, absolute humidity, and temperature. Appl Environ Microbiol 84:e00551-e00518. https://doi.org/10.1128/ AEM.00551-18

47. Rodríguez-Lázaro D, Cook N, Ruggeri FM, Sellwood J, Nasser A, Nascimento MSJ, D'Agostino M, Santos R, Saiz JC, Rzeżutka A, Bosch A, Girones R, Carducci A, Muscillo M, Kovač K, DiezValcarce M, Vantarakis A, von Bonsdorff C-H, de Roda Husman AM, Hernández M, van der Poel WHM (2012) Virus hazards from food, water and other contaminated environments. FEMS Microbiol Rev 36:786-814. https://doi.org/10.1111/j.1574-6976. 2011.00306.x
48. Roos YH (2012) Materials science of freezing and frozen foods. In: Bhandari B, Roos YH (eds) Food Materials Science and Engineering. Wiley Blackwell, Hoboken, pp 136-150

49. Rzeżutka A, Cook N (2004) Survival of human enteric viruses in the environment and food. FEMS Microbiol Rev 28:441-453

50. Sánchez G (2015) Processing strategies to inactivate hepatitis A virus in food products: A critical review. Compr Rev Food Sci Food Saf 14:771-784. https://doi.org/10.1111/1541-4337.12154

51. Sánchez G, Bosch A (2016) Survival of enteric viruses in the environment and food. In: Goyal SM, Cannon JL (eds) Viruses in Foods, 2nd edn. Springer, Cham, pp 367-392. https://doi.org/10. 1007/978-3-319-30723-7 13

52. Stals, A., Baert, L., Van Coillie, E. and Uyttendaele, M. 2012. Extraction of food-borne viruses from food samples: a review.

53. Stine SW, Song I, Choi CY, Gerba CP (2005) Effect of relative humidity on preharvest survival of bacterial and viral pathogens on the surface of cantaloupe, lettuce, and bell peppers. J Food Prot 68: $1352-1358$

54. van Doremalen N, Morris DH, Holbrook MG, Gamble A, Williamson BNM, Tamin A, Harcourt JL, Thornburg NJ, Gerber SI, Lloyd-Smith JO, de Wit E, Munster VJ (2020) Aerosol and surface stability of SARS-CoV-2 as compared with SARS-CoV1. N Engl J Med 382:1564-1567. https://doi.org/10.1056/ NEJMc2004973

55. Virtanen A, Joutsensaari J, Koop T, Kannosto J, Yli-Pirilä P, Leskinen J, Mäkelä JM, Holopainen JK, Pöschl U, Kulmala M, Worsnop DR, Laaksonen A (2010) An amorphous solid state of biogenic secondary organic aerosol particles. Nature 467:824-827. https://doi.org/10.1038/nature09455

56. Weber TP, Stilianakis NI (2008) Inactivation of influenza A viruses in the environment and modes of transmission: a critical review. J Infect 57(5):361-373. https://doi.org/10.1016/j.jinf.2008.08.013

57. Woese C (1960) Thermal inactivation of animal viruses. Ann N Y Acad Sci 83:741-751. https://doi.org/10.1111/j.1749-6632.1960. tb40943.x

58. Zayas G, Chiang MC, Wong E, MacDonald F, Lange CF, Senthilsevan A, King M (2012) BMC Pulm Med 12:11

59. Zhang Y, Qu S, Xu L (2019) Progress in the study of virus detection methods: the possibility of alternative methods to validate virus inactivation. Biotechnol Bioeng 116:2095-2102

60. Zuber S, Butot S, Baert L (2013) Effects of treatments used in food processing on viruses. In: Smulders FJM, Nørrung B, Budka $\mathrm{H}$ (eds) Foodborne Viruses and Prions and Their Significance for Public Health. Food safety assurance and veterinary public health no. 6, pp 113-136. https://doi.org/10.3920/978-90-8686-780-6

Publisher's Note Springer Nature remains neutral with regard to jurisdictional claims in published maps and institutional affiliations. 